\title{
Modelling Analysis of Methods for Wind Turbine Annual Energy Production
}

\author{
Dian Wang ${ }^{1, a}$, Huixin $\mathrm{Li}^{1, \mathrm{~b}}$ Faming $\mathrm{Wu}^{1, \mathrm{c}}$ and Lei Wang ${ }^{1, \mathrm{~d}}$ \\ ${ }^{1}$ CRRC ZHUZHOU INSTITUTE CO.,LTD.

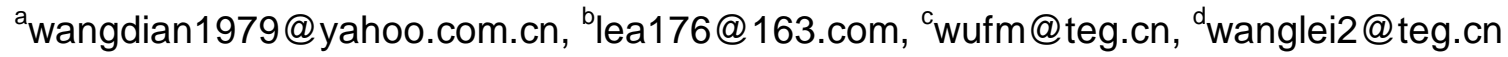

\begin{abstract}
Keywords: Wind turbine, Power curve, AEP
Abstract. Wind turbine power curve essentially captures the wind turbine performance which shows the relationship between the wind turbine energy output and hub height wind. This paper presents a reasonable method to model power curve of a wind turbine, and compares with measured power curve based on IEC61400-12. The final annual energy production(AEP) calculated by this method can be found less difference than energy yield by measured. This investment indicates a way which can accurately approximate the final realistic AEP.
\end{abstract}

\section{Introduction}

Evaluation of energy yield from a site is imperative for profit analysis, and the predictive accuracy is critical toward the developer of the wind farm. The power generated by a wind turbine and annual energy production of a wind farm is usually a part of pre-feasibility study for any site which is plan to commencement of works. Estimation of AEP , on one hand, is based on a long time anemometry and with the wind data information the air density, annual mean wind speed, wind power concentration, wind frequency distribution, wind shear, turbulence intensity and so on are also can be attained. On the other hand, is based on the wind turbine information which offered by manufacturer such as power curve, the hub height, and the availability factor.

Subject to the reasonableness of the general need to develop wind farms in the theoretical generating capacity estimated based on the following principles. The first is that Wind resource assessment is based on the national and industry standards related to ensure that the measured wind resource has a good representation in the future of the wind farm area. The second is that the impact of the factors to be considered are reasonable and calculation method is proper. Factors affecting the grid electricity is multifaceted, Generally, the focus of several factors to be considered including air density, Wind frequency distribution, wake, control and turbulence, blade contamination, wind turbine efficiency, power curve guaranteed rate, auxiliary power and line loss, downtime with climate impacts and so on. $\mathrm{n}$ addition to these general factors there are other factors which less consideration such as wind shear, wind turbine arrangement, tower height, etc. Obviously, computing constraints associated with wind farms AEP is complex combinations. The estimate AEP could not be sufficiently accurate. By analyzing the power input conditions and calculation constraints factor, and to analyze the factors that often easy to overlook, identify its sensitivity and the degree of influence, and then calculate the result of these factors caused a change in the magnitude of the change generation. On a comprehensive grasp of various factors such as project development early generation can make reasonably accurate estimates in the project evaluation process to focus attention and control of restrictive factors, in order to improve the accuracy of project evaluation and reliable economic effect.

It is usual for wind turbine manufacturers to publish a power curve characterising their machine and moreover a power curve with some comfort margin that will be guaranteed to be met for purposes of commercial trading or exaggerate the wind turbine energy production for winning the bid easily. Normally, annual energy production (AEP) based on the performance of power curve from manufacturers may not be accuracy enough. 


\section{Wind Energy}

The energy available in the wind varies as the cube of the wind speed, so an understanding of the characteristics of the wind resource is critical to all aspects of wind energy exploitation, from the identification of suitable sites and predictions of the economic viability of wind farm projects through to the design of wind turbines themselves, and understanding their effect on electricity distribution networks and consumers.

The power output, $\mathrm{P}$, from a wind turbine is given by the well-known expression:

$$
P=\frac{1}{2} C_{p} \rho A V^{3} \text {. }
$$

where $\rho$ is the density of air, $C p$ is the power coefficient, $A$ is the rotorswept area, and $V$ is the wind speed.

Wind turbine power curve. A wind turbine usually commences power production operation at a minimum (cut-in) wind speed or when the wind drops below a safe operating maximum (cut-out) wind speed. The energy output of a wind turbine is naturally the result of its power performance over a operating period which from cut-in wind to cut-out wind. The power curve is reflects the operating characteristics and power characteristics of the wind turbine.

$$
P(x)=\left\{\begin{array}{lc}
0 & \left(x<V_{\text {cutin }}, x>V_{\text {cutout }}\right) \\
\frac{1}{2} C_{p} \rho A x^{3} & \left(V_{\text {cuin }} \leq x<V_{\text {rated }}\right) \\
P_{r} & \left(V_{\text {rated }} \leq x \leq V_{\text {cutout }}\right)
\end{array} .\right.
$$

From the foregoing analysis can be found the main influencing factors about the power curve are often multifaceted. Sorted by forming a power curve can be divided into pre-bid power curve and actual operating power curve. The actual wind farm wind resource conditions are not the same, pre-bid power curve which is theoretical power curve from wind turbine manufacturers is calculated based on the wind turbine model and the actual wind farm wind resource. In the early running of the wind farms AEP estimate is only possible using the theoretical power curve. Theoretical power curves can be divided into static and dynamic power curve of the power curve. Static power curve is the steady-state calculations, it does not consider the wind turbulence, inflow angle, wind shear, wind momentary fluctuations of wind bias, wake, turbulence control and other factors. Using the IEC61400-1 requirements, with the NTM wind model, dynamic power curve obtained. The dynamic power curve reflects the actual operation of wind turbines, and the dynamic characteristics of the wind turbine.

Annual energy production calculation.The annual energy yield is calculated by integrating the power curve for the turbine together with a Weibull or user-defined distribution of hourly mean wind speeds. The power curve is defined at a number of discrete wind speeds, and a linear variation between these points is assumed.

The Weibull distribution is defined by:

$$
F(V)=1-e^{-\left(\frac{V}{c \bar{V}}\right)^{k}} \text {. }
$$

where $F$ is the cumulative distribution of wind speed $V$. Thus the probability density $f(V)$ is given by:

$$
f(V)=-k \frac{V^{k-1}}{(c \bar{V})^{k}} e^{-\left(\frac{V}{c \bar{V}}\right)^{K}} \text {. }
$$

Here $k$ is the Weibull shape factor, and $c$ is the scale factor. For a true Weibull distribution, these two parameters are related by the gamma function:

$$
c=1 / \Gamma\left(1+\frac{1}{k}\right) .
$$

The annual energy yield is calculated as

$$
E=Y \int_{V_{\text {cutin }}}^{V_{\text {cutout }}} P(V) f(V) d V \text {. }
$$


Where $P(V)$ power curve, i.e. electrical power as a function of wind speed, $Y$ the length of a year, taken as 365 days or 8760 hours.

The result is further multiplied by the availability of the turbine, which is assumed for this purpose to be un-correlated with wind speed.

Frequently a steady state power curve is used, combined with a distribution of hourly mean wind speeds. For a more accurate calculation, it is desirable to use a dynamically calculated power curve given as the average power from a series of simulations based on a model of the turbulent wind field. It is common practice to use 10-minute simulations to capture the effects of turbine dynamics and wind turbulence. Strictly speaking, the appropriate distribution to use in this case would be one representing the distribution of 10-minute mean wind speeds in a year. For a Weibull distribution, this will typically have a slightly smaller shape factor than that for hourly means.

If the wind power generation reduction is $\gamma$,then the virtual Annual energy yield is: $E_{a}=\gamma \times E$.

\section{Modeling for power curve}

Efficiency of wind turbine drive train components.Power train energy losses are modelled as a combination of mechanical losses and electrical losses in the generator (including the frequency converter in the case of variable speed turbines).

Mechanical losses in the gearbox and/or shaft bearings can be modelled as a loss torque, here it is given by a simplified empirical model, where the gearbox ratio $N$ and $T_{G}$ is rated torque of the generator :

$$
M_{\text {loss }}=0.03 \times 1.085 \times N \times T_{G} \text {. }
$$

The electrical losses may specified by Linear model: This requires a no-load loss $L N$ and an efficiency, where the electrical power output $P e$ is related to the generator shaft input power $P s$ by:

$P_{e}=\varepsilon \times\left(P_{s} \times L_{N}\right)$.

Modification at rated power. Variable wind turbine control system is active in operation around rated wind speed in the operation of a typical pitch regulated. Control of the wind turbine is effected by a rapid reaction of generator to torque fluctuations and a slower reaction of the pitch system to limit speed variations. Wind turbine at rated wind speed operates to maximize energy capture and to avoid excessive power and load levels. In the actual operation energy production less than rated power at the steady rated wind state. The following analysis illustrates the effect of turbulence on power at the wind speed around the rated range.

The expected energy production (kW) at rated wind, $V=V r$ and $P=P r$, is:

$E\left(P_{r}\right)=\frac{1}{\sqrt{2 \pi} \sigma} \int_{V \text { cutin }}^{\text {Vcutout }} P(v) e^{\left\{\frac{\left(V-V_{r}\right)^{2}}{2 \sigma^{2}}\right.} d v$.

If $k=\frac{1}{2} C_{p} \rho A$, integration of equation (1) and (2), rated power will simplify to:

$$
E\left(P_{r}\right) \approx P_{r}-\frac{k \sigma}{\sqrt{2 \pi}} \text {. }
$$

The turbulence intensity, I , can be defined as: $I=\sigma / V$.

At the rated wind $\sigma=I \times V_{r}$, then, $E\left(P_{r}\right)=P_{r}-\frac{k I V_{r}}{\sqrt{2 \pi}}$.

\section{Results}

With a 2.5MW horizontal axis wind turbine parameters, and the energy losses module has been defined in GL bladed software which are based on the method discussed above. A power curve can be easy calculated. And the difference with dynamic power curve by measured based on IEC61400-12 at the same atmosphere condition has been depicted in the following figure. 


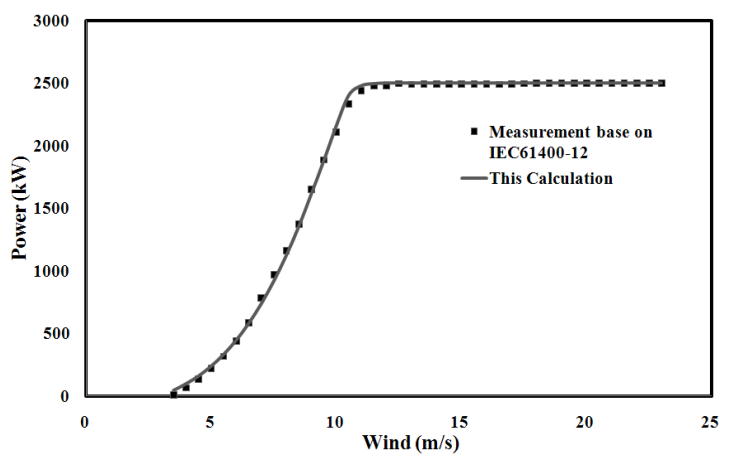

Fig 1 Power curve of a $2.5 \mathrm{MW}$ wind turbine

Table 1 AEP of a $2.5 \mathrm{MW}$ wind turbine

\begin{tabular}{|c|c|c|c|}
\hline $\begin{array}{c}\text { Annual Mean wind speed } \\
{[\mathrm{m} / \mathrm{s}]}\end{array}$ & $\begin{array}{c}\text { Energy production by measured } \\
{[\mathrm{kWh}]}\end{array}$ & $\begin{array}{c}\text { Energy production by this calculation } \\
{[\mathrm{kWh}]}\end{array}$ & $\begin{array}{c}\text { Deviatio } \\
\mathrm{n} \\
{[\%]}\end{array}$ \\
\hline 7 & 8306283 & 8353538 & $0.56 \%$ \\
\hline 7.5 & 9294517 & 9341374 & $0.54 \%$ \\
\hline 8 & 10211970 & 10252491 & $0.42 \%$ \\
\hline
\end{tabular}

From the result on Fig1 and Table1, we can see that the calculation power curve can reflect the real energy output corresponding wind basically, moreover the predictions of this method for AEP has been found to be generally within $0.6 \%$ of the measured results.

\section{Conclusion}

In the method presented in this paper, based on wind turbine model,the turbulence intensity and air density are used as the input data, and then power curve can be obtained by GL bladed. Using the calculation power curve and the data of Weibull distribution function of sites,evaluation of energy yield can be easy calculated accurately and reliability. In addition, this method can be used effectively for improving construction planning, and economic conditions of wind farms for specific areas. Such investigation can help wind farm owner to evaluate a approximate final realistic AEP and to choose proper wind turbine for profiting analysis.

\section{References}

[1] J.Sumner,C.Masson.Influence of Atmospheric Stability on Wind Turbine Power Performance Curves.Journal of Solar Energy Engineering, 2006, 128(4):531-538.

[2] O.Uluyol,G.Parthasarathy,W.Foslien,K.Kim.Power Curve Analytic for Wind Turbine Performance Monitoring and Prognostics.Annual Conference of the Prognostics and Health Management Society, Montreal QC,2011.

[3] BP Hayes,I Ilie,A Porpodas,SZ Djokic.Equivalent power curve model of a wind farm based on field measurement data.Powertech, IEEE Trondheim, 2011:1-7.

[4] W.Rozenn,CS.Michael,LJ. Torben,PS.Uwe.Simulation of shear and turbulence impact on wind turbine performance. Campus Ris $\phi$-R-1722(EN), January 2010.

[5] C.Carrillo,A.F.Obando Montano,Review of power curve modeling for wind turbines. Renewable and sustainable Energy reviews .21(2013) 572-581.

[6] Peter Jamieson. Innovation in Wind Turbine Desgin.(John Wiley \& Sons, Ltd., Publication,2011). 